\section{Conclusions}

A set of experimental heat capacities for the alkaline-earth-oxides, reported in part I was analysed. From the results it was shown:

- that there is a systematic change in the shape of the vibration frequency spectra, which is virtually identical to those of the alkaline fluorides, having nearly the same mass ratio as the oxides and having the same ratio of elastic constants at low temperatures;

- that therefore the oxides do not exhibit any specified divalent ionic character;

- that all oxides show a positive anharmonic con- tribution to the specific heat, which was excluded in this analysis.

If this qualitative interpretation of the results seems clear a quantitative discussion of these results is not yet possible, due to the lack of accurate experimental data on density, elastic constants, coefficient of dilatation and compressibility and their variation with temperatures for these oxides as for the fluorides; and finally there is a need for the exact frequency spectra, which should be deduced from neutron scattering data. In connection with these experimental data more detailed studies of the lattice dynamics of alkaline-earth-oxides should be required.

\title{
Thermoelectric Properties in Silver Chloride-Alkali Chloride Fused Mixtures*
}

\author{
Cesare Sinistri and Elisabetta Pezzati \\ Institute of Physical Chemistry, University of Pavia, Italy \\ (Z. Naturforsch. 25 a, 893-897 [1970] ; received 31 March 1970)
}

\begin{abstract}
The initial thermoelectric power of the molten salt mixtures $(\mathrm{Ag}+\mathrm{Me}) \mathrm{Cl}(\mathrm{Me}=\mathrm{Li}, \mathrm{Na}, \mathrm{Rb}, \mathrm{Cs})$ has been measured at various temperatures around $800^{\circ} \mathrm{C}$ using a silver electrode thermocell. In addition the thermoelectric power of molten pure $\mathrm{AgCl}$ is reported.

These data have been used to obtain relative values of the heats of transport of the alkali cations in pure salts. Moreover the global behaviour of these mixtures in respect to an ideal model for the heat and electricity transport is discussed.
\end{abstract}

Though the first measurements of thermoelectric power in molten salts date back to the end of the last century, systematic work has appeared only recently. HAASE ${ }^{1}$ has given a concise discussion of the data presented in the literature. For a full phenomenological description of the system, initial and stationary state values of the thermoelectric power would be desirable. Nevertheless, as it has already been shown ${ }^{2}$, values of thermoelectric power at zero time in molten binary mixtures enable to draw some information on the global behaviour of the systems in respect to the heat and electricity transport phenomena.

This work reports measurements of the thermoelectric power at zero time on the molten binary mixtures $\mathrm{AgCl}+\mathrm{MeCl}$ where $\mathrm{Me}=\mathrm{Li}, \mathrm{Na}, \mathrm{Rb}, \mathrm{Cs}$. The system $\mathrm{AgCl}+\mathrm{KCl}$ has previously been described $^{3}$.

Reprints request to Prof. Cesare Sinistri, Istituto di Chimica Fisica, Università di Pavia, 1-27 100 Pavia, Italia, Viale Taramelli.

* This work is a part of a communication given at the "Euchem Conference on Molten Salts (Salice Terme - May
The surveys have been made in the thermocell:

final stage $\left|\mathrm{Ag}_{(\mathrm{s})}\right|(\mathrm{Ag}+\mathrm{Me}) \mathrm{Cl}_{(\mathrm{l})}\left|\mathrm{Ag}_{(\mathrm{s})}\right|$ final stage

at various temperatures around $800{ }^{\circ} \mathrm{C}$ and at different compositions.

\section{Experimental}

The "U" shaped cell, made of quartz, was placed in a nickel block divisible into three pieces. The differential heating of one of the two arms of the cell was obtained by means of thermocoax resistences (Sodern). An electrode-holder was placed in each of the two arms of the cell to support the point shaped silver electrode. The measuring thermocouple in platinel was placed near the electrode and shielded by a thin quartz tube. The differences in temperature ranged from 5 to $15{ }^{\circ} \mathrm{C}$. All the other experimental features were analogous to those described in previous works ${ }^{2,3}$.

1968)". It has been supported by the financial aid of the CNR (Rome).

1 R. HAase and J. Richter, Z. Naturforsch. 24 a, 418 [1969].

2 C. Sinistri, Z. Naturforsch. 21 a, 753 [1966]. - C. SinI-

STRI and C. MARGHeritis, Z. Naturforsch. 23 a, 1155 [1968].

3 C. Sinistri and E. PezzAti, Z. Naturforsch. 22 a, 590 [1967]. 
The $\mathrm{AgCl}$ was freshly prepared; the $\mathrm{LiCl}$ (C. Erba RP) was carefully dried according to literature; $\mathrm{NaCl}$ (C. Erba RP), $\mathrm{RbCl}$ and $\mathrm{CsCl}$ (Merck p. a.) were prefused and dried before use.

\section{Results and Discussion}

The value of the thermoelectric power at zero time, $\varepsilon(=\mathrm{d} \Phi / \mathrm{d} T)$ for a thermocell such as (1) can be obtained by means of the methods of the thermodynamics of irreversible processes ${ }^{4}$. If the velocity of the $\mathrm{Cl}^{-}$ion is used as reference (Hittorf's system), $\varepsilon$ is given by:

$\varepsilon=\frac{1}{F}\left(S_{\mathrm{Ag}}-S_{\mathrm{Ag}^{+}}-S_{\mathrm{e}}^{*}-t_{\mathrm{Ag}^{+}} \frac{Q_{\mathrm{Ag}+}^{*}}{T}-t_{\mathrm{Me}^{+}} \frac{Q_{\mathrm{Me}^{+}}^{*}}{T}\right)$

where $F=$ Faraday's constant; $S_{\mathrm{Ag}}=$ atomic entropy of metallic silver; $S_{\mathrm{Ag}^{+}}=$partial molar entropy of the $\mathrm{Ag}^{+}$ion in the melt; $S_{\mathrm{e}}^{*}=$ entropy of transport of the electron in metallic silver; $t=$ transport numbers; $Q^{*}=$ heats of transport; $T=$ mean temperature of the system.

It has been shown ${ }^{2}$ that a good tool for the study of the global behaviour of the mixture is the $\Psi$ function defined as:

$$
\begin{aligned}
\Psi & \equiv F\left(\varepsilon-\varepsilon_{\mathrm{AgCl}}\right)-R \ln x_{\mathrm{Ag}^{+}} \\
& ={ }^{0} Q_{\mathrm{Ag}^{+}}^{*}-Q_{\mathrm{Ag}^{+}}^{*}+t_{\mathrm{Me}^{+}} \frac{Q_{\mathrm{Ag}^{+}}^{*}-Q_{\mathrm{Me}^{+}}^{*}}{T}-s_{\mathrm{Ag}^{+}}^{\mathrm{e}}
\end{aligned}
$$

If data for the excess entropy $s_{\mathrm{Ag}+}^{\mathrm{e}}$ are available, the $\Psi$ function changes into $\Psi^{\prime}$ :

$$
\Psi^{\prime} \equiv \Psi+s_{\mathrm{Ag}+}^{\mathrm{e}}
$$

Eqs. (3) - (4), with the condition that transport numbers are continuous functions of the concentration, give $\Psi^{\prime} \rightarrow 0$ when $x_{\mathrm{AgCl}} \rightarrow 1, \quad$ and $\Psi^{\prime} \rightarrow \Psi_{0}^{\prime}=(1 / T) \cdot\left({ }^{0} Q_{\mathrm{Ag}^{+}}^{*}-{ }^{0} Q_{\mathrm{Me}^{+}}^{*}\right)$ when $x_{\mathrm{AgCl}} \rightarrow 0$. Now, it has been proposed ${ }^{2}$ that a mixture behaves ideally when: a) the heats of transport of the ions are constant and independent of concentration; b) the transport numbers of the two cations are equal to the respective ionic fractions. Then the $\Psi_{\text {id. func- }}^{\prime}$ tion depends linearly on concentration according to:

$$
\Psi_{\text {id. }}^{\prime}=\frac{{ }^{0} Q_{\mathrm{Ag}^{+}}^{*}-{ }^{0} Q_{\mathrm{Me}^{+}}^{*}}{T}\left(1-x_{\mathrm{AgCl}}\right) .
$$

The behaviour of the mixture can then be discussed on the basis of deviations from ideality.

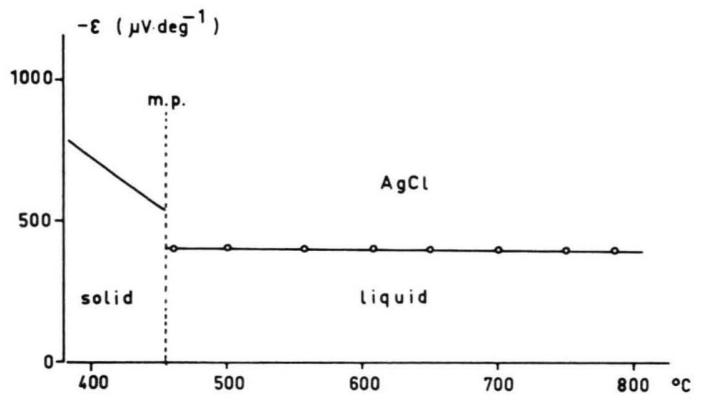

Fig. 1. Value of the thermoelectric power for pure fused $\mathrm{AgCl}$ as a function of the temperature.

Figure 1 reports the values of thermoelectric power of pure fused $\mathrm{AgCl}$. These data can be expressed

\begin{tabular}{|c|c|c|c|c|c|c|c|c|}
\hline \multirow[t]{2}{*}{$x_{\mathrm{AgCl}}$} & \multicolumn{2}{|c|}{$\begin{array}{c}\text { System } \\
(\mathrm{Ag}+\mathrm{Li}) \mathrm{Cl}\end{array}$} & \multicolumn{2}{|c|}{$\begin{array}{c}\text { System } \\
(\mathrm{Ag}+\mathrm{Na}) \mathrm{Cl}\end{array}$} & \multicolumn{2}{|c|}{$\begin{array}{c}\text { System } \\
(\mathrm{Ag}+\mathrm{Rb}) \mathrm{Cl}\end{array}$} & \multicolumn{2}{|c|}{$\begin{array}{c}\text { System } \\
(\mathrm{Ag}+\mathrm{Cs}) \mathrm{Cl}\end{array}$} \\
\hline & $-\varepsilon$ & $\Psi$ & $-\varepsilon$ & $\Psi$ & $-\varepsilon$ & $\Psi$ & $-\varepsilon$ & $\Psi$ \\
\hline 1.00 & 397 & 0.00 & 397 & 0.00 & 397 & 0.00 & 397 & 0.00 \\
\hline 0.90 & 387 & 0.44 & 371 & 0.81 & 353 & 1.22 & 336 & 1.62 \\
\hline 0.80 & 380 & 0.84 & 361 & 1.27 & 333 & 1.92 & 323 & 2.15 \\
\hline 0.70 & 375 & 1.22 & - & - & 326 & 2.35 & 318 & 2.53 \\
\hline 0.65 & - & - & 360 & 1.71 & - & - & - & - \\
\hline 0.60 & 372 & 1.59 & - & - & 324 & 2.70 & 316 & 2.88 \\
\hline 0.50 & 372 & 1.95 & 358 & 2.28 & 323 & 3.08 & 316 & 3.24 \\
\hline 0.40 & - & - & 358 & 2.72 & - & - & - & - \\
\hline 0.35 & 371 & 2.68 & - & - & 320 & 3.86 & 316 & 3.95 \\
\hline 0.30 & - & - & 362 & 3.20 & - & - & - & - \\
\hline 0.20 & 374 & 3.73 & 369 & 3.84 & 324 & 4.88 & 320 & 4.97 \\
\hline 0.10 & 386 & 4.83 & 395 & 4.62 & 345 & 5.77 & 333 & 6.05 \\
\hline 0.05 & 400 & 5.88 & - & - & 384 & 6.25 & 355 & 6.92 \\
\hline
\end{tabular}
by the relation:

$$
\varepsilon_{\mathrm{AgCl}}=\left(-410+0.016 t\left({ }^{\circ} \mathrm{C}\right)\right) \mu \mathrm{V} \mathrm{deg}-1 .
$$

Table 1. Interpolated values of the thermoelectric power $\varepsilon(\mu \mathrm{V} \mathrm{deg}-1)$ and of the $\Psi$ function (cal $\left.\mathrm{deg}^{-1} \mathrm{~mole}^{-1}\right) \mathrm{for}^{\mathrm{the}}$ systems $(\mathrm{Ag}+\mathrm{Me}) \mathrm{Cl}(\mathrm{Me}=\mathrm{Li}, \mathrm{Na}, \mathrm{Rb}, \mathrm{Cs})$ at $800^{\circ} \mathrm{C}$.

${ }^{4}$ H. SchönerT and C. Sinistri, Z. Elektrochem. 66, 413 [1962]. 
Figures 2 and 3 report the thermoelectric power (at zero time) plotted as a function of the mean temperature of the four examined mixtures.

The absolute values of $\varepsilon$, relative both to the pure salt and to the mixtures, decrease more or less as the temperature increases. In order to prevent spontaneous reactions of the silver electrode with the alkali chloride, mixtures with concentration less than $x_{\mathrm{AgCl}}=0.05$ have not been studied.

Beside the compositions, Table 1 lists the $\varepsilon$ values at the mean temperature of $800{ }^{\circ} \mathrm{C}$. Also the $\Psi$
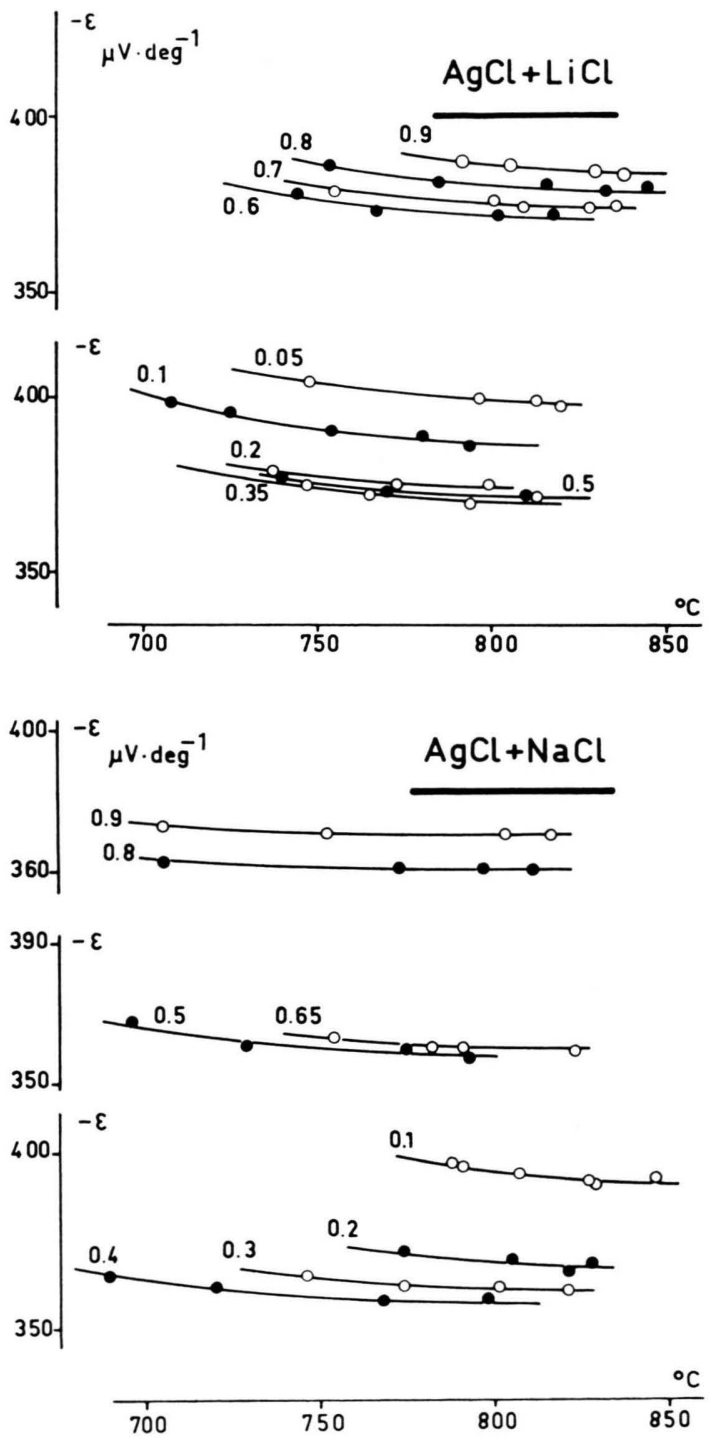

Fig. 2. Values of $\varepsilon$ vs. temperature for the $(\mathrm{Ag}+\mathrm{Li}) \mathrm{Cl}$ and $(\mathrm{Ag}+\mathrm{Na}) \mathrm{Cl}$ systems. The numbers near the curves are the molecular fractions of $\mathrm{AgCl}$.
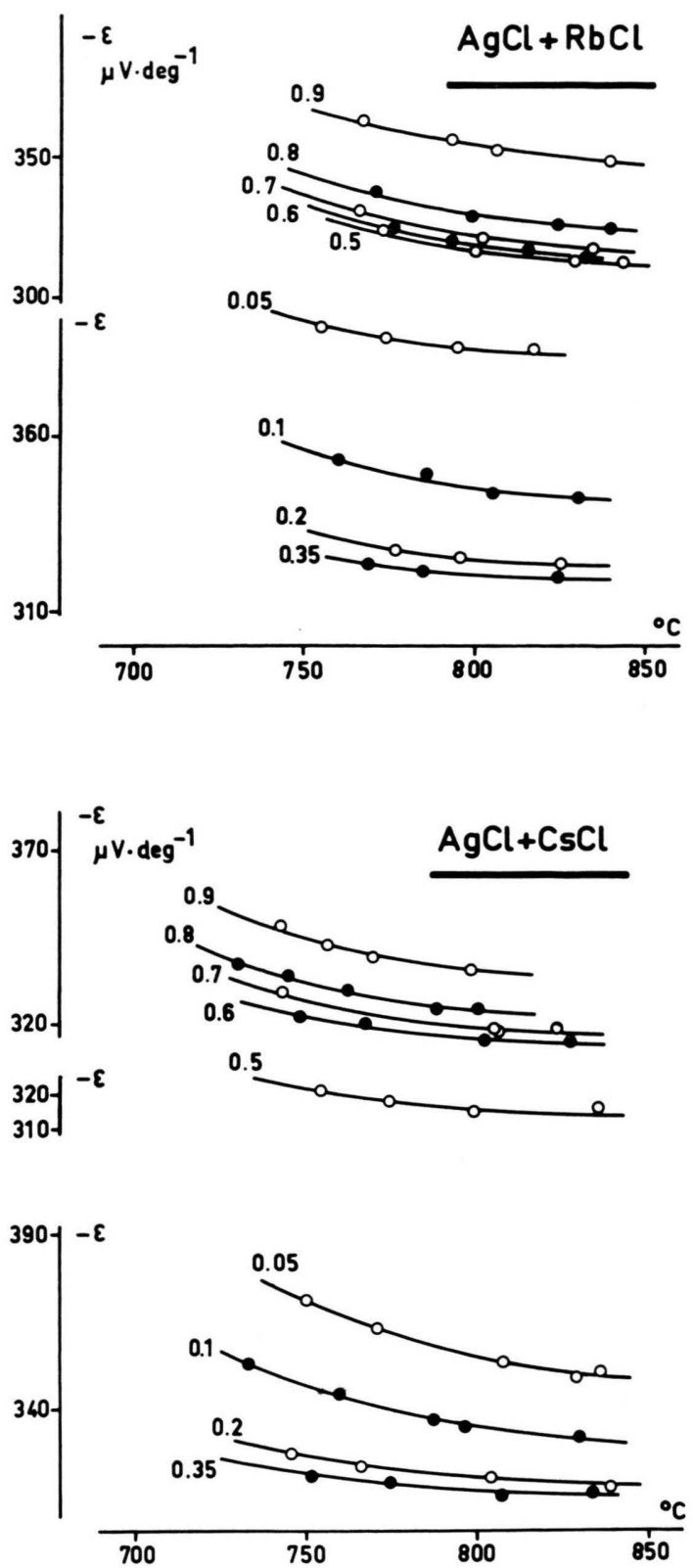

Fig. 3. Values of $\varepsilon$ vs. temperature for the $(\mathrm{Ag}+\mathrm{Rb}) \mathrm{Cl}$ and $(\mathrm{Ag}+\mathrm{Cs}) \mathrm{Cl}$ systems. The numbers near the curves are the molecular fractions of $\mathrm{AgCl}$.

function values, obtained from Eq. (3), appear in this table.

Figure 4 shows $\varepsilon$ versus concentration for the five binary systems $\mathrm{AgCl}+(\mathrm{Li}, \mathrm{Na}, \mathrm{K}, \mathrm{Rb}, \mathrm{Cs}) \mathrm{Cl}$.

As it can be observed, these mixtures behave in a similar way except the one containing the $\mathrm{Li}$ ion. This 


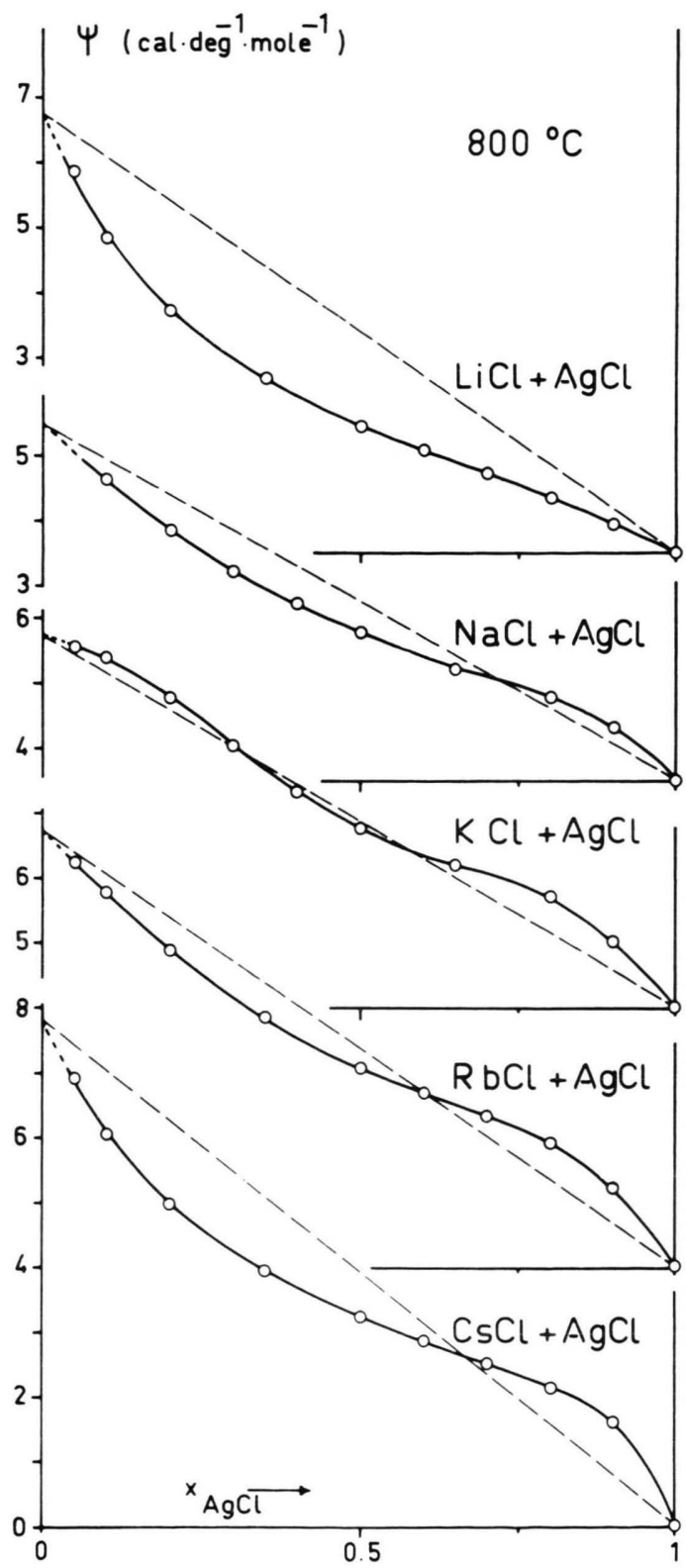

Fig. 4. Values of $\varepsilon$ vs. composition for the systems $\mathrm{AgCl}+\mathrm{MeCl}$ $(\mathrm{Me}=\mathrm{Li}, \mathrm{Na}, \mathrm{K}, \mathrm{Rb}, \mathrm{Cs})$ at $800^{\circ} \mathrm{C}$.

mixture shows a function $\varepsilon$ versus concentration intersecting the ones of the other systems at low concentration of silver chloride.

The heat and electricity transport phenomena of these systems can be analyzed on the basis of the $\Psi$-function test. For these mixtures systematic values of $s_{\mathrm{Ag}^{+}}^{\mathrm{e}}$ are not directly available.

For $(\mathrm{AgCl}+\mathrm{LiCl}) \mathrm{HERSH}$ and $\mathrm{KLEPPA}^{5}$ reported an excess entropy value (corresponding to $x_{\mathrm{AgCl}}$
$=0.5$ ) of -0.04 e. u. Analogous data have been reported for the (silver + alkali) bromides molten mixtures ${ }^{6}$. On the basis of electrochemical data of the literature, $\mathrm{JANZ}^{7}$ recommends the following values:

$$
\begin{aligned}
& \text { for }(\mathrm{AgCl}+\mathrm{LiCl}) \\
& \text { for }(\mathrm{AgCl}+\mathrm{NaCl}) \\
& \text { for }(\mathrm{AgCl}+\mathrm{KCl})
\end{aligned}
$$

$$
\begin{aligned}
& s_{\mathrm{AgCl}}^{\mathrm{e}}=0 ; \\
& s_{\mathrm{AgCl}}^{\mathrm{e}}=0.5 x_{\mathrm{NaCl}}^{2} \quad \text { e. u.; }
\end{aligned}
$$
no estimate can be made as the data are too scattered.

Therefore these excess entropies are small and the calculated values for the $\Psi$ function should not differ sensibly from the corresponding $\Psi^{\prime}$ values. In Fig. 5 the behaviour of the $\Psi\left(x_{\mathrm{AgCl}}\right)$ functions is reported for the five examined systems.

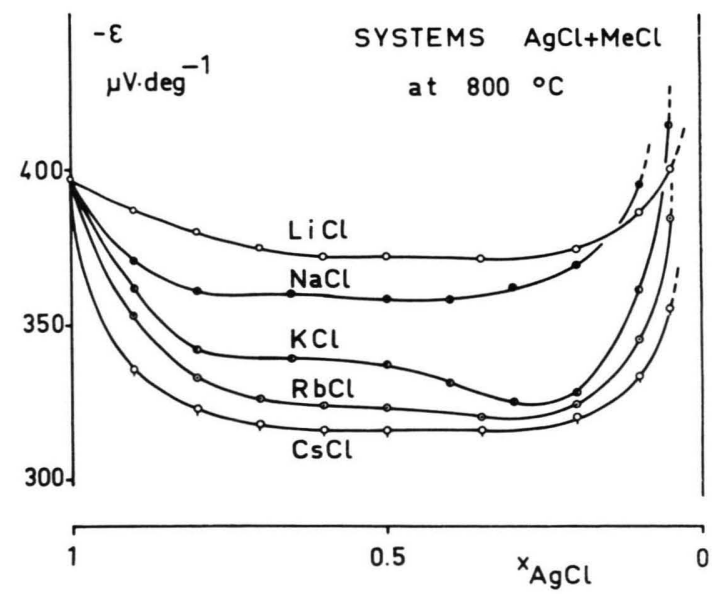

Fig. 5. Behaviour of the $\Psi$ functions for the systems $\mathrm{AgCl}$ $+\mathrm{MeCl}(\mathrm{Me}=\mathrm{Li}, \mathrm{Na}, \mathrm{K}, \mathrm{Rb}, \mathrm{Cs})$. Dashed lines represent the ideal behaviour.

The $\Psi$ values extrapolated at $x_{\mathrm{AgCl}}=0\left(\Psi_{0}\right)$ are reported in Table 2 near the quantities ${ }^{0} Q_{\mathrm{Ag}^{+}}^{*}-{ }^{0} Q_{\mathrm{Me}^{+}}^{*}$, calculated assuming $\left(s_{\mathrm{Ag}^{+}}^{\mathrm{e}}\right)_{0}=0$. As it can be seen the relative values of the heats of transport are all ranging between $6-8 \mathrm{cal} \mathrm{deg}^{-1} \mathrm{~mole}^{-1}$ : they should be considered as provisional until an exact evaluation of the term $\left(s_{\hat{A} g^{+}}^{\mathrm{e}}\right)_{0}$ will be available.

FISCHER ${ }^{8}$ has measured the thermoelectric power of the cells $\mathrm{Cl}_{2} / \mathrm{MeCl}$ (molten) $/ \mathrm{Cl}_{2}$. He obtained the

5 L. S. Hersh and O. J. Kleppa, J. Chem. Phys. 42, 1309 [1965].

6 J. H. Hildebrand and E. J. Salstrom, J. Amer. Chem. Soc. 54. 4257 [1932]. - L. S. Hersh, A. NAvrotSKY, and O. J. Kleppa, J. Chem. Phys. 42, 3752 [1965].

7 G. J. JANZ and Chr. G. M. DijkHuis, Section 1 of "Molten Salts: Volume 2", NSRDS-NBS 28, Washington 1969.

8 W. FisCHER, Z. Naturforsch. 21 a, 281 [1966]. 


\begin{tabular}{lcc}
\hline Salt & $\begin{array}{c}\Psi_{0} \\
(\text { cal deg }\end{array}$ & $\begin{array}{c}0 Q_{\mathrm{Ag}^{+}}^{*}-{ }^{0} Q_{\mathrm{Me}^{+}}^{*} \\
(\mathrm{Kcal} / \mathrm{mole})\end{array}$ \\
\hline $\mathrm{LiCl}$ & 6.8 & 7.3 \\
$\mathrm{NaCl}$ & 5.5 & 5.9 \\
$\mathrm{KCl}$ & 5.7 & 6.1 \\
$\mathrm{RbCl}$ & 6.7 & 7.2 \\
$\mathrm{CsCl}$ & 7.8 & 8.4 \\
\hline
\end{tabular}

Table 2. Values of $\Psi_{0}$ (obtained by extrapolation of $\Psi$ for $x_{\mathrm{AgCl}} \rightarrow 0$ ) and relative values of the heats of transport at $800{ }^{\circ} \mathrm{C}$.

heats of transport of the single ions through the following set of calculations:

$$
\varepsilon \stackrel{S_{\mathrm{Cl} 2}}{\longrightarrow} S_{\mathrm{Cl}^{-}}^{*} \stackrel{S_{\mathrm{MeCl}}}{\longrightarrow} S_{\mathrm{Me}^{+}}^{*} \stackrel{\text { Eqs.(7)(8) }}{\longrightarrow}{ }^{0} Q_{\mathrm{Me}^{+}}^{*} .
$$

In the first of these steps one goes from the thermoelectric power to the entropy of transport of the $\mathrm{Cl}^{-}$ion $\left(S_{\mathrm{Cl}-}^{*}\right)$ knowing the entropy of the chlorine gas; in the second one, the entropy of transport of the cation $\left(S_{\mathrm{Me}^{+}}^{*}\right)$ is obtained knowing the entropy of the molten chloride. Finally the third step uses the relation

$$
S_{\mathrm{Me}^{+}}=\frac{1}{2}\left(S_{\mathrm{MeCl}}+\frac{3}{2} R \ln \left(M_{+} / M_{-}\right)\right)
$$

which was first proposed by WAGNER ${ }^{9}$ without the correction term of the mass ratio $\left(M_{+} / M_{-}\right)$between cation and anion and finally in form (7) by PITZER ${ }^{10}$.

The entropy value of the cation $\left(S_{\mathrm{Me}^{+}}\right)$can be used to obtain the heat of transport ${ }^{0} Q_{\mathrm{Me}^{+}}^{*}$, from the relation:

$$
S_{\mathrm{Me}^{+}}^{*} \equiv S_{\mathrm{Me}^{+}+{ }^{0} Q_{\mathrm{Me}^{+}}^{*} / T} .
$$

The ${ }^{0} Q_{\mathrm{Me}^{+}}^{*}$ values obtained by FisCHER through this procedure are reported in Table 3 along with the differences ${ }^{0} Q_{\mathrm{Ag}^{+}}^{*}-{ }^{0} Q_{\mathrm{Me}^{+}}^{*}$ (first and second column). They are rather small and must be considered merely as indicatives in view of the great uncertainties connected with the experimental values of $\varepsilon, S_{\mathrm{Cl}_{2}}, S_{\mathrm{MeCl}}$ and with the problem of the precision degree of Eq. (7). As information, the third and fourth column of Table 3 report the values of ${ }^{0} Q_{\mathrm{Me}^{+}}^{*}$ and $\left({ }^{0} Q_{\mathrm{Ag}^{+}}^{*}-{ }^{0} Q_{\mathrm{Me}^{+}}^{*}\right)$ as calculated using the primitive form of Eq. (7) as proposed by WAGNER.

The ideal behaviour of these systems, given by Eq. (5), is shown in Fig. 5 by the dashed lines. As it can be noted, the greatest deviations from ideality are those of the mixtures containing the $\mathrm{Li}$ and $\mathrm{Cs}$ ions. The mixture $(\mathrm{Ag}+\mathrm{K}) \mathrm{Cl}$ is almost ideal, whereas intermediate deviations are shown by the mixtures containing $\mathrm{Na}$ and $\mathrm{Rb}$ ions. Also remarkable is the area near the pure silver chloride. Apart from the system containing $\mathrm{Li}$, in this area there are typical positive deviations from ideality increasing with the cations' radii. In the other areas negative deviations are prevailing.

It is interesting to observe that, if the heats of transport are supposed additive, the ratio $\Psi_{0} / \Psi$ gives directly the value of Hittorf's transport number of the alkali cation in the mixture. On the other hand, if Hittorf's transport numbers of the cations are assumed equal to the respective ionic fractions, the same ratio brings into evidence the deviations from additivity of the heats of transport of the ions. Probably these two factors are both determinant.

\begin{tabular}{lcccc}
\hline \multicolumn{1}{c}{ Salt } & ${ }^{0} Q_{\mathrm{Me}^{+}}^{*}$ & ${ }^{0} Q_{\mathrm{Ag}^{+}}^{*}-{ }^{0} Q_{\mathrm{Me}^{+}}^{*}$ & ${ }^{0} Q_{\mathrm{Me}^{+}}^{*}$ & ${ }^{0} Q_{\mathrm{Ag}^{+}}^{*}-{ }^{0} Q_{\mathrm{Me}^{+}}^{*}$ \\
\hline $\mathrm{LiCl}$ at $880^{\circ} \mathrm{K}$ & 0.2 & 2.1 & -2.0 & 5.4 \\
$\mathrm{NaCl}$ at $1073^{\circ} \mathrm{K}$ & 0.0 & 2.3 & -0.7 & 4.1 \\
$\mathrm{KCl}$ at $1044^{\circ} \mathrm{K}$ & 0.6 & 1.7 & 0.7 & 2.7 \\
$\mathrm{RbCl}$ at $995^{\circ} \mathrm{K}$ & 1.5 & 0.8 & 2.8 & 0.6 \\
$\mathrm{CsCl}$ at $918^{\circ} \mathrm{K}$ & 1.2 & 1.1 & 3.0 & 0.4 \\
$\mathrm{AgCl}$ at $728^{\circ} \mathrm{K}$ & 2.3 & - & 3.4 & - \\
\hline
\end{tabular}

Table 3. Heats of transport (in kcal/mole) calculated according to FisCHER ${ }^{8}$. In columns 1 and 2 are reported the values obtained using PITZER's evaluation ${ }^{10}$ for the entropy of the single ion [Eq. (7)] ; in columns 3 and 4 the ones obtained using WAGNER's evaluation 9 .
9 C. WAGner, Ann. Physik 3, 629 [1929] ; 6, 370 [1930].

10 K. S. Pitzer, J. Phys. Chem. 65, 147 [1961]. 